\title{
Technological innovation using a test car for conventional lines
}

\author{
K. Katano, M. Matsuhashi, Y. Kouno \& K. Anzai \\ East Japan Railway Company, Japan
}

\begin{abstract}
In order to carry out test runs efficiently, an experimental train which was named MUE-Train was developed. JR East remodeled a series 209 EMU into MUETrain. The concepts of the modification were that the structure could be equipped with verification target devices and that MUE-Train could run on various conventional lines for matching test conditions of each device.

A variety of devices and systems have been installed on MUE-Train, and test runs have been carried out. A major one of them is a train communication network which is named INTEROS developed with the purpose of improving reliability and service. INTEROS is based on 100Mbps Ethernet transmission technologies. Another one is a ground equipment monitoring system. The system consists of devices which monitor status of items on the ground such as tracks, overhead wires and so on. The system has been developed to reduce maintenance costs, as well as to improve precision of measurement and inspection. The system aims to be installed on a commercial car and to collect ground equipment data at high frequency on the car by using INTEROS in the near future.

This paper describes the overview of MUE-Train's configuration and its test runs.

Keywords: test car, experimental train, air spring car-body tilting system, monitoring system, train communication network.
\end{abstract}

\section{Introduction}

East Japan Railway Company (JR East) is working on research and development for innovation of conventional lines mainly in the Tokyo metropolitan area. At the stage of research and development of vehicle technologies, test runs using an actual car are essential to verify the structure and the function of new devices and 
systems. Therefore, in order to carry out test runs efficiently, an experimental train which was named MUE-Train (Multipurpose Experimental Train) was developed. JR East remodeled a series 209 EMU used as a commuter train into MUE-Train.

In the first remodeling, the 209 EMU was converted into MUE-Train as a train for test runs, and the construction was completed in 2008. Test runs to examine an air spring car-body tilting system, a ground equipment monitoring system and so on were carried out until December 2009.

In the second remodeling, a next-generation Train Communication Network (TCN), INTEROS (INtegrated Train communication/control networks for Evolvable Railway Operation System) [1] was mounted on MUE-Train, and the work was completed in September 2011. JR East has been developing INTEROS in order to replace TIMS (Train Information Management System) adopted into current commuter trains with INTEROS. Adequacy of INTEROS' functions has been verified by test runs towards the completion of the system.

Figure 1 shows the appearance of MUE-Train. The exterior design represents "Bright future and hope" with white belt and "Construction of new railway system by gathering new technologies from many fields" with block pattern.

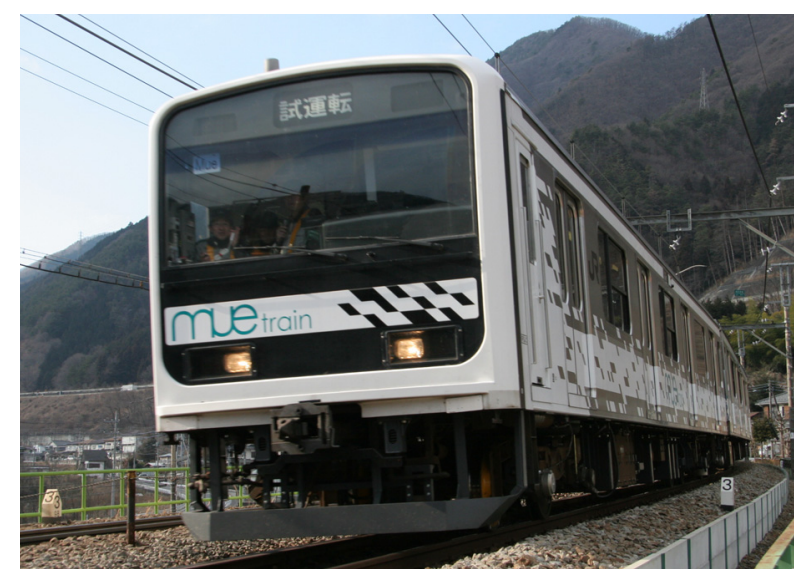

Figure 1: Appearance of MUE-Train.

\section{Train set configuration}

Figure 2 shows the set configuration of MUE-Train. MUE-Train was the set of 7 cars, 4M3T in the first remodeling. Depending on the type of test, test runs were performed with the set of 6 cars except No. 4 car. After the second remodeling, it has been fixed to the set of 6 cars, $4 \mathrm{M} 2 \mathrm{~T}$.

\section{The first remodeling}

In the first remodeling, main structures and devices of the series 209 EMU were untouched. The concepts of the modification were as follows. 


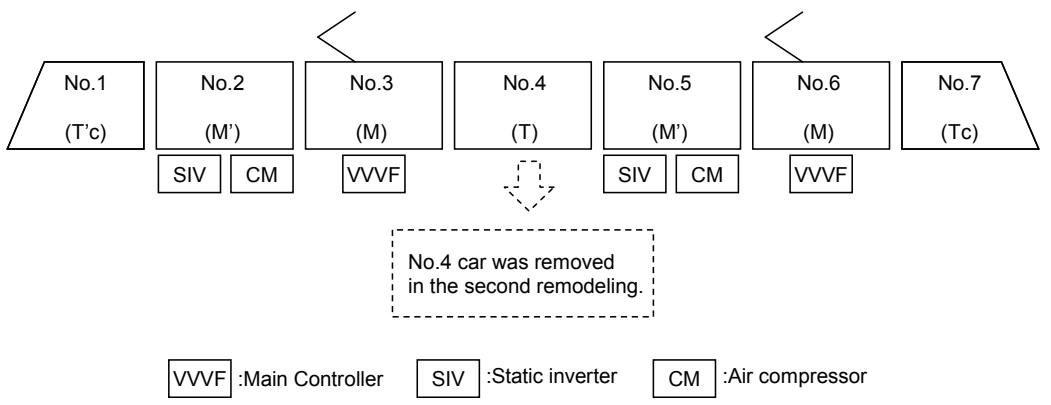

Figure 2: $\quad$ Set configuration of MUE-Train.

The structure is able to run on various conventional lines for matching test conditions of each test device and system.

The structure is able to be equipped with verification target devices.

The structure is suitable for the work in the car on the test run.

\subsection{Adaptation to various conventional lines}

In order to run various conventional lines, ATS-P type and ATS-SN type were mounted as safety equipment in addition to D-ATC installed originally. ATS-P type was mounted inside the car to make space for other test target devices equipped under the car. D-ATC shares an on-board antenna with ATS-P type by using added switching function.

There is a line which has tunnels of the smaller cross section in conventional lines. Therefore, pantographs of No. 3 car and No. 6 car were changed to lower ones when being folded.

\subsection{Mounted systems for verification}

An air spring car-body tilting system was mounted on No. 1 car and No. 2 car, and the pipe laying work was carried out for the system. With the purpose of securing clearance during body tilting, the height of car-body was lowered by the bogie adjustment such as a change of wheel diameter and the form of the rain water gutter was changed partly.

Brake control devices were changed from control by the bogie to control by the axle, and slide detecting devices were also changed for the improvement of brake performance.

A ground equipment monitoring system was also installed. The system consists of devices which monitor status of items on the ground, such as tracks and overhead wires. As for the tracks, a track-material monitoring device and a track measurement device were mounted on No. 7 car. As for the overhead wires, an overhead line monitoring device was mounted on No. 6 car.

Moreover, an antenna was mounted on the roof of No. 1 car for the verification of general-purpose wireless communication such as Worldwide 
Interoperability for Microwave Access (WiMAX). An on-board antenna of ATS$P$ type was installed under the floor of No. 5 car to monitor status of safety equipment.

\subsection{Adaptation to the work on the test run}

Seats of the commuter train were removed partly, and desks and chairs for the measurement tasks were placed. Semi-eternal type couplers were replaced with tight lock couplers in order to facilitate the split and combine for work efficiency of test preparation. Figure 3 shows the status in No. 7 car of MUE-Train.

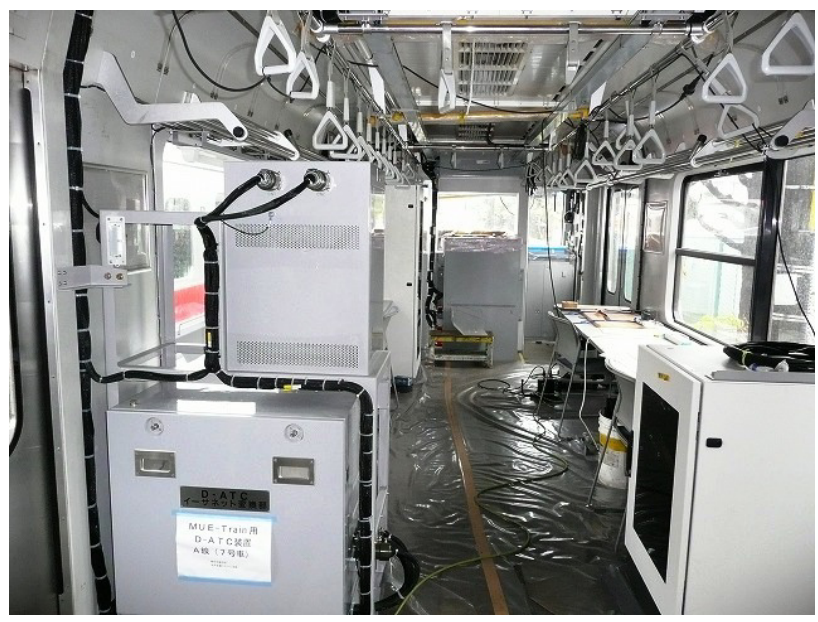

Figure 3: $\quad$ Status in No. 7 car of MUE-Train.

\section{The second remodeling}

In the second remodeling, INTEROS was mounted. Devices which make up INTEROS were installed, and main devices which are controlled by INTEROS, such as main controller, static inverter, brake control devices and devices in driver's cabin represented by master controller, were replaced with new ones. In addition, wiring for control was upgraded to wiring of Ethernet transmission. In this way, large-scale construction was executed through the second remodelling.

\section{Outline of verifications on MUE-Train}

\subsection{Air spring car-body tilting system}

An air spring car-body tilting system is one of car-body tilting systems for the improvement of ride comfort and speed-up on curves. JR EAST has adopted the system into cars of Shinkansen, series E5 and series E6. Other railway operators also adopt the system into cars for conventional lines in Japan. However, 


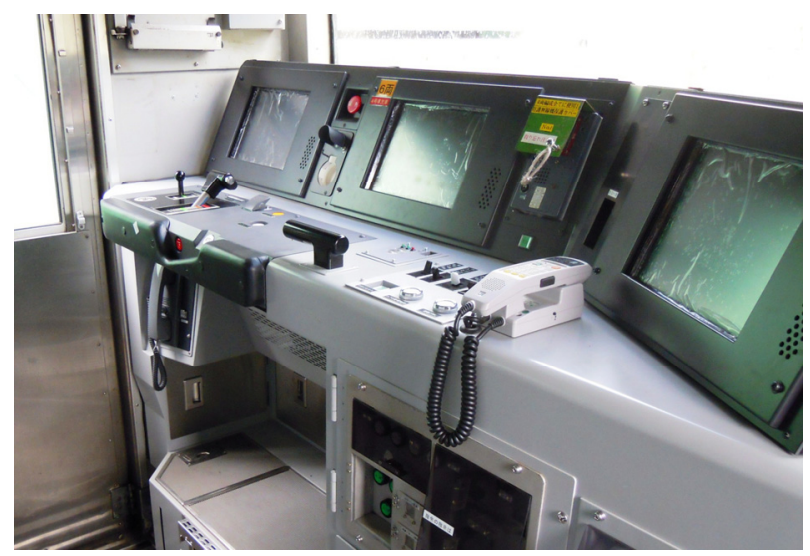

Figure 4: $\quad$ Status of driver's cab.

verifications are essential to adopt it for conventional lines which have continuation of small radius curves and S-shaped curves. Through the test runs of MUE-Train, the inspection had been carried out in order to pick out the problems to be improved for the adoption.

\subsection{Ground equipment monitoring system}

In order to inspect the condition of tracks and overhead wires, irregularity of the ground equipment is measured several times a year along conventional lines by inspection cars which are called "East-i". Irregularity which cannot be inspected with the inspection car is regularly inspected by patrolling on foot. On the other hand, downsizing and cost reduction of measurement devices are expected because of technological advances in recent years. With the purpose of reducing maintenance costs, as well as improving inspection quality and increasing frequency of inspection, JR East has developed a ground equipment monitoring system which is installed on a commercial car. The functions of the system have been verified by test runs of MUE-Train. The system was composed of a trackmaterial monitoring device, a track measurement device and an overhead wires condition monitoring device.

The purpose of the track material monitoring device is to take images with cameras located under the floor and automatically detect abnormalities: missing fishplate bolts, loosened rail fastening, shifted rail pads, metal flow at gluedinsulation rail, etc. The track measurement device collect data which can measure track irregularity: gauge, alignment, longitudinal level, cross level and twist. It is able to downsize the current measurement device mounted on the inspection car [2].

The overhead wires condition monitoring device consists of a pantograph for measurement of acceleration, a contact wire measurement unit, a data transmission unit and a recorder. The system's purpose is to find trouble of overhead wires early using the acceleration data of the pantograph and video 
data. The system records video data from the contact wire measurement unit and data acceleration from sensor of the pantograph synchronously, and sends the data to the data transmission unit by infrared communications. Figure 5 shows the overhead wires condition monitoring device on the MUE- Train.

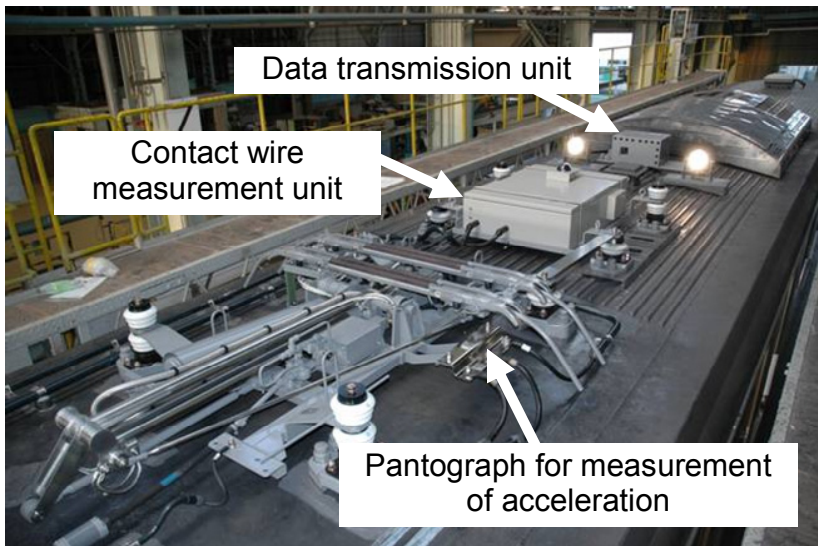

Figure 5: Overhead wires condition monitoring device.

\subsection{INTEROS}

\subsubsection{Background}

TCN has become important to control a whole train. It handles information such as train operation instructions from a driver to each device, status information of the devices and various crew-assistance functions. JR East has been adopting TIMS as a TCN into many railcars mainly in the greater Tokyo area. TIMS has been contributing to reduction of train wires and advancement of functions for driving and maintenance. However, the transmission capacity is limited in $10 \mathrm{Mbps}$ (Mega bit per second) because of TIMS' transmission technology, which is ARCNET.

On the other hand, Internet has been widely used, and Ethernet technologies have become easy to use since its large capacity, cost performance, and the number of engineers. Therefore, Ethernet-based TCN using Ethernet technologies is expected to be developed in order to enhance scalability. Meanwhile, International standardization of Ethernet-based TCN has proceeded.

In above environment, higher functionality, scalability, reliability and cost performance are required for TCN. Consequently, JR East has been developing 100Mbps-Ethernet-based TCN, INTEROS.

\subsubsection{Concepts of INTEROS}

INTEROS has three development concepts: "Enhancement of reliability", "Enhancement of scalability" and "Adaptation to international standards". As shown in Figure 6, networks are divided into three depending on functions. The Control Network deals with functions related to driving such as run and stop. 
The Status Monitoring Network collects information of monitoring systems for each device in order to realize detailed assistance of maintenance work. The ground equipment monitoring system mentioned above is also connected to this network, and INTEROS gathers data from the monitoring system. The Information Network works for transmission of contents of pictures and movies for passengers.

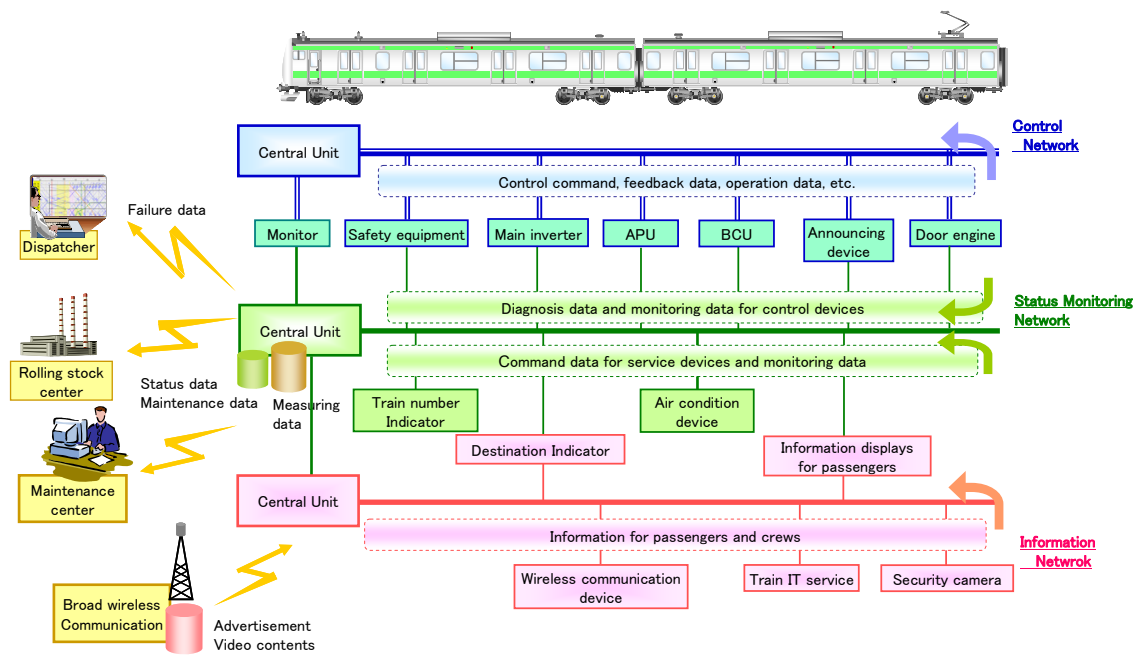

Figure 6: Outline of INTEROS' network.

\subsubsection{Main specifications}

Table 1 shows main transmission specifications of INTEROS compared with TIMS. In addition, we have established a train-to-ground radio connection using general-purpose wireless communication recently.

Table 1: $\quad$ Main transmission specifications.

\begin{tabular}{|l|l|l|}
\hline & \multicolumn{1}{|c|}{$\begin{array}{c}\text { TIMS } \\
\text { (Series E233) }\end{array}$} & \multicolumn{1}{|c|}{ INTEROS } \\
\hline Transmission scheme & $\begin{array}{l}\text { ARCNET (Main line) } \\
\text { HDLC (Branch line) }\end{array}$ & Ethernet \\
\hline Transmission rate & $10 \mathrm{Mbps}$ & $100 \mathrm{Mbps}$ \\
\hline Signal amplitude & $16 \mathrm{Vp}-\mathrm{p}$ & $\begin{array}{l}8 \mathrm{Vp}-\mathrm{p} \text { (Main line) } \\
2 \mathrm{Vp}-\mathrm{p} \text { (Branch line) }\end{array}$ \\
\hline Redundancy & Duplicated system & $\begin{array}{l}\text { Control data : Duplicated system } \\
\text { Status data and Message data : Single system }\end{array}$ \\
\hline
\end{tabular}




\section{Conclusion}

MUE-Train had been remodeled to install verification target systems: an air spring car-body tilting system, a ground equipment monitoring system, INTEROS, etc. Adequacy of the systems has been inspected by test runs in conventional lines in Tokyo metropolitan area, and we have collected valuable data for research and development.

In recent years, a new speed detecting system mounted on MUE-Train has been examined by test runs. The system which has been used in automobile field is expected to replace present axle-driven generators for detecting train speed with rotational speed of an axle. Adoption of the system will contribute to improving measurement precision, downsizing speed detecting systems and improving maintainability.

As the name, "MUE (MUltipurpose Experimental Train)", we will make good use of the test car in various researches and developments which need verifications using an actual car.

\section{References}

[1] Kawasaki, J. and Kouno, Y., Outline of INTEROS Development, JR East Technical Review, No. 20-summer2011, http://www.jreast.co.jp/e/ development/tech/pdf 20/Tec-20-40-45eng.pdf

[2] Matsuda, H., Takigawa, M, Nanmoku, T. and Yazawa, E., Track test monitoring system using a multipurpose experimental train, Computers in Railways XII, WIT press, pp. 701-708, 2010. 